\title{
Research on the Organizational Citizenship Behavior Continuum and Its Consequences
}

\author{
(C) Higher Education Press and Springer-Verlag 2011
}

\begin{abstract}
Through literature review and induction from management practices, this paper firstly identifies four subtypes of organizational citizenship behavior (OCB), namely altruistic OCB based on personality, responsible OCB based on reciprocity, instrumental OCB based on self-interest, and compulsory OCB based on stress. The four OCB subtypes constitute an OCB continuum in the order of an individual's degree of voluntariness. Both the positive and negative impacts of the four OCB subtypes on organizations and individuals are analyzed. Conclusions, limitations and future research directions are presented.
\end{abstract}

Keywords organizational citizenship behavior (OCB), altruistic OCB, responsible $\mathrm{OCB}$, instrumental $\mathrm{OCB}$, compulsory $\mathrm{OCB}$

\section{Introduction}

In an era of knowledge-based economy, a majority of modern organizations have adopted the strategy of flat organization structure, reengineered and team-based

Received June 30, 2010

Yongjun Zhang $(\bowtie)$

School of Management, Huazhong University of Science and Technology, Wuhan 430074,

China

E-mail: zyj2yl@yahoo.com.cn

Jianqiao Liao

School of Management, Huazhong University of Science and Technology, Wuhan 430074, China

E-mail: jimliao@hust.edu.cn

Jun Zhao

School of Management, Huazhong University of Science and Technology, Wuhan 430074, China

E-mail: Zhjun_521@sina.com 
work frameworks to cope with intensified challenges along with globalized competition. This shift increases the importance of individual initiative and cooperation. As a key extra-role behavior promoting the effective functioning of organizations, organizational citizenship behavior (OCB) has attracted increasing interests from both scholars and managers alike (Organ, 1997).

A literature review shows that existing OCB study has, to a large degree, concentrated on why individuals want to perform $\mathrm{OCB}$ and what kind of outcomes do these behaviors induce. As for the antecedents of OCB, scholars have achieved a general consensus that $\mathrm{OCB}$ is the outcome of interaction between individuals and contextual variables, and pointed out that when employees perceive organizational justice and high quality leader-member exchange relationship, they will exhibit OCB actively on the basis of positive reciprocity norm (Lavelle et al., 2007). As for the outcome of OCB, Podsakoff et al. (2000) summarized that OCB can improve organizational performance and efficiency from seven aspects. Therefore, in a long period, there are two basic findings on OCB research: OCB is employees' voluntary behavior and is beneficial to organization. For example, Moorman and Blakely (1995) indicated that individuals have the freedom to decide whether to exhibit OCB or not. It is therefore very difficult for managers to inspirit the emergence or punish the "shortage" of OCB by formal contract requests. Becton et al. (2008) pointed out that managers should encourage employees to perform OCB for its benefits.

However, some researchers and practitioners have cast doubt on the above conclusions. Is OCB equal to employees' voluntary behavior? Is it true that OCB exerts only positive influences? Recently, in addition to "voluntary" OCBs, many "instrumental" and "compulsory" OCBs have been found in organizations, "illusive OCB" may not only conceal potential managerial problems in organizations, but also increase managerial costs. In a meta-analysis of individual- and organizational-level consequences of OCB, Podsakoff et al. (2009) pointed out that the potential consequences of OCB are not always positive and therefore should be treated differently. Recently, along with the development of market economy and the spread of materialism, Chinese people are becoming more and more diverse and utilitarian, and the "Lei Feng" type of altruism behaviors are now becoming less popular. Meanwhile, the instrumental $\mathrm{OCB}$ of meeting self-interest and the compulsory $\mathrm{OCB}$ of bowing to pressure are becoming norm in modern Chinese organizations - OCB is taking on a multiple form, so does its impact on organization and individual. Therefore, this paper firstly identifies four subtypes of OCB through reviewing literatures and summarizing the practice of management, and then constructs an OCB continuum based on the degree of voluntariness, and discusses their potential influence on organization and individuals respectively. Finally, we develop several propositions for future research on OCB. 
This paper contributes to knowledge on OCB mainly in the following three aspects. Firstly, through systemic review and summary, we identify four subtypes of OCBs, namely altruistic OCB which is based on personality, responsible OCB which is based on reciprocity, instrumental OCB which is based on self-interest and compulsory OCB which is based on stress. Different from previous dimension research of OCB, not only can these four types of OCBs explore the forms of OCB, but they also are useful for studying the antecedents and consequences of OCB. Secondly, we construct an OCB continuum based on these four types of OCB, ranging from compulsory OCB to altruistic OCB in the order of degree of voluntariness. The continuum lays a solid foundation for future OCB research and measurement. Finally, we analyze the potential positive and negative consequences of these four types of OCB on organization and individuals respectively.

\section{Types of Organizational Citizenship Behavior}

\subsection{OCB}

Organ (1988) firstly defined OCB as an "individual behavior that is discretionary, not directly or explicitly recognized by the formal reward system and it on the whole promotes the effective functioning of the organization." There are several similar concepts as OCB, such as extra-role behaviors, pro-social organizational behaviors, organizational spontaneity, and contextual performance. According to the definition, OCB is an extra-role behavior that is beneficial to organization. It is not a job responsibility required by the formal employment contract, but it consists of a series of informal cooperative actions. Organ (1988) identified three basic characteristics of OCB, namely "not job role demand," "not in the range of performance appraisal," and "beneficial to organizational functions." Later, Organ (1997) modified this definition, and considered OCB as a contextual performance similar to that of proposed by Borman and Motowidlo (1993): OCB can provide support for the fostering of broader organizational, social, and psychological environment.

\subsection{Four OCB Subtypes}

Recently, scholars have probed into the subtypes of OCBs. For example, Van Dyne et al. (1995) thought that OCBs could be divided into affiliative citizenship behavior and challenging citizenship behavior. Korsgaard et al. (2010) put forward the rewarded and unrewarded organizational citizenship behavior based on paying you back or paying me forward. As per our earlier discussion, previous research considered OCB as the outcome of individual variables which interact 
with contextual variables, and emphasized that the theory foundations are social exchange theory and the norm of reciprocity. However, OCB is not employees' perception of their jobs or employers. On the contrary, it is a type of proactive behaviors by which employees choose to engage because they regard it as tools to meet certain needs or satisfy specific motives (Penner et al., 1997). In addition, Vigoda-Gadot (2007) put forward the concept of "Compulsory Citizenship Behavior" (CCB). Spector and Fox (2010) also indicated that several OCBs are not employees' voluntary action but caused by job environment. Although OCB is employees' voluntary behavior, previous studies rarely paid attention to the degree of voluntariness of different OCBs. Hence, through literatures review and summarization of managerial practices in modern organizations, we identify four subtypes of OCBs based on the degree of voluntariness.

\subsubsection{Altruistic OCB Based on Personality}

Early research on OCB found that personality is not only the best predictable variable, but also one reason that can explain employees' behavior diversity. Smith et al. (1983) confirmed that OCB is an exhibition of pro-social disposition propensity. Borman and Motowidleo (1993) emphasized the predictable effect of personality on OCB. Finkelstein (2006) indicated that employees' pro-social value can influence their OCB. Organ and Ryan (1995) pointed out that agreeableness, conscientiousness, positive affectivity, and negative affectivity in FFM can predict OCB. Grant and Mayer (2009) found that individual's pro-social motivation can predict the challenging citizenship behavior (such as voice). Besides, there are some people like to help others and do not care for their gains or losses in reality. There are also many employees who exhibit OCB just for their inherent personality. For example, some people, though keep certain independence to their organization, offer to voluntarily protect organizational reputation, deter others' stealing behaviors in organization, provide ideas for organization development, help co-workers resolving job problems and so on. Under such circumstances, exhibition of OCB is not due to responsibility for organizational justice perception, appraisal stress or the pursuit of reward, but because they simply enjoy doing so (Zhang and Liao, 2009).

Bolino (1999) pointed out that some people like to help others because of their inherent personality, just like the charity of Samaria, one's contributions and helping behaviors arise from intrinsic motivation and altruism completely, in which they can gain intrinsic satisfaction and never care for money and rewards (Tang et al., 2008). They do not purposely exhibit for reputation, and do not stop exhibiting these behaviors for outside pressure. On the contrary, they exhibit OCB out of certain personality traits or just for personal interest. Hence, we define altruistic and personality-based OCB as the behavior that determined by 
personalities, and that do not be affected by or influenced less by the outside contextual variables. Without question, altruistic and personality-based OCB is useful for organization.

Proposition 1 Altruistic OCB based on personality is determined intrinsically, and the outside contextual factor is of little impact on it. It is therefore a completely voluntary behavior.

\subsubsection{Responsible OCB Based on Reciprocity}

As previously mentioned, social exchange theory and the norm of reciprocity are the foundation theories of OCB. Its basic assumption is that when employees apperceive organization justice, they will exhibit OCB to pay back proceeding from the norm of reciprocity (Lavelle et al., 2007). Thus, from the organization perspective, managers should treat employees fairly and respectfully, as well as trust them in order to motivate their OCB. However, if employees form positive psychology contract with organization, their many behaviors can't be determined by themselves, and OCB convert from discretionary to required behavior (Tumipseed and Wilson, 2009). In other words, from the morality and ethic viewpoint, employees have responsibility to actively exhibit OCB to pay back organizational fair treatment and leader's respect, care and support. Baker et al. (2006) found that the corporate ethical values can promote ethical behaviors and OCB through organizational commitment; Korsgaard et al. (2010) applied the theory of other orientation to differentiate rewarded OCB and unrewarded OCB and found that the obligation to reciprocate benefits already received from another ("paying you back") was more strongly influenced by unrewarded OCB. Bergeron (2007) found that employees need to exhibit OCB that the role demands to pay back organizational training, promotion, and reward. When employees apperceive organizational fair treatment, paying back the other benefits become obligation and responsibility, OCB become role demand behavior that employees can not freely determine for social exchange and the norm of reciprocity (Tumipseed and Wilson, 2009).

In China, Confucianism ethics, such as "favors must be returned," "the favor of a drop of water should be rewarded with the gratitude of a fountain of water," have formed the foundation of Chinese culture. As a result, Ren, Yi, Li, Zhi, Xin (benevolence, righteousness, courtesy, intelligence, and credibility) and other Confucian doctrines have become people's principles of behavior. Hence, we define responsible $\mathrm{OCB}$, which is based on reciprocity, as an obligation to pay back other's favor based on social exchange etiquette and the norm of reciprocity. Currently, large amount of evidence has shown that the responsible OCB has positive impact on organizational functions (Podsakoff et al., 2000).

Proposition 2 The theoretical foundations for responsible OCB based on 
reciprocity are social exchange theory and the norm of reciprocity. The obligation to reciprocate makes OCB transform from discretionary behavior to required behavior.

\subsubsection{Instrumental OCB Based on Self-Interest}

Generally speaking, behaviors are driven by motivation, and so does OCB. In fact, OCB is not a reaction or response, per se, to employees' perception of their jobs or employers. Rather, it is proactive behavior in which employees choose to perform because they can use it to meet certain needs or to satisfy motives (Penner et al., 1997). Bolino (1999) proposed that when the exhibition of OCB brings benefits to employees, they would tend to perform more OCBs. Hui et al. (2000) found that employees who perceived that going beyond the call of duty would help them get promoted tend to perform higher levels of OCB. However, they also found that, after promotion, these same individuals would cut back on their OCBs. Grant and Mayer (2009) indicated that impression management (IM) motives moderate the relationship between pro-social motive and affiliative citizenship behavior, and the influence of pro-social motive on affiliative citizenship behavior becomes stronger when impression management motives are higher. Korsgaard et al. (2010) found that expected reciprocity (paying me forward) influences rewarded OCB significantly. Becton et al. (2008) indicated that because many managers take OCB into account when conducting performance appraisal or offering reward, promotion, and training, many employees pursuing organizational rewards would use IM tactics to perform OCB actively. When the motive behind OCB is IM, a "good soldier" becomes a "good performer." Meanwhile, OCB turns into instrumental tools for people to fulfill their self-serving aims (Wei, 2006).

IM describes the efforts made by an individual to create, maintain, protect, or otherwise alter an image held by a target audience (Bozeman and Kacmar,1997), such as ingratiation, pleasing leaders, purposely help coworkers, and some self-promotions in the presence of leaders or coworkers and so on. It has been found that IM is related to OCB. For example, Fandt and Ferris (1990) first pointed out the potential overlap of IM tactics and OCB. Yun et al. (2007) found that employees engage in OCB to enhance their image at work, particularly when they have job roles that are not well defined. They thus concluded that IM is a "viable" theoretical approach for explaining OCB in organizations. Snell and Wong (2007) differentiated pro-organizational motives through a qualitative interview study and OCB attributed primarily to IM, i.e. alleged pseudo-OCB. Hence, we define instrumental OCB which is based on self-interest as behaviors which use IM tactics for self-serving aims. To a certain extent, instrumental OCB based on self-interest is useful for improving organizational performance, despite 
of the fact that these behaviors are actually adopted to serve personal purposes.

Proposition 3 Instrumental OCB based on self-interest is determined by the pursuit of rewards. Generally speaking, IM tactics are this type of OCBs forms.

\subsubsection{Compulsory OCB Based on Stress}

Nowadays, along with the intensifying competition in the labor market and global financial crisis, employees sometimes have to perform extra-role behaviors to retain their jobs, turning OCB into expected behaviors at work. It has been found that several factors tend to leave people with no choice but perform OCB. For example, Brockner (1988) found that due to fearing of losing their jobs, employees would work hard to prove their values to an organization. Gilboa et al. (2008) also found that when employees perceive that high performance can help organizational success and assure job security, the organizational dismissal policy is based on individual contribution to organization, and job insecurity can improve employees' work effort and performance. Vigoda-Gadot (2007) indicated that supervisors in control of organization resources exert powerful impact on employees. Besides, it is up to the leaders to determine what types of organizational behaviors are OCBs. All of these will result in abusive supervision and exploitation, forcing employees to bear some extra-role jobs and giving rise to CCB. Spector and Fox (2010) also found that in fact OCBs are not employees' voluntary behavior but caused by work context, such as leader's demand, dependent task, coworker's failing in jobs or laze in team-based work frameworks. In addition, group stress (George and Jones, 1997) and performance appraisal (Zhang and Liao, 2009) can also lead to more OCBs.

The young generation of Chinese employees, such as the so-called "post- $80 \mathrm{~s}$ " and "post-90s," is characterized with a higher degree of individualism, autonomy and independence, and a lower degree of voluntary OCB, as compared with the "old" generation of Chinese employees. However, work pressure faced by the new generation of employees also increase. As a result, they have to exhibit more OCB to guarantee job security. Compulsory OCB has become the norm in organizations in the knowledge era. We hence define compulsory OCB as a type of context-forced OCB. By comparison, Compulsory OCB brings more benefits for organization than it brings to individuals.

Proposition 4 Compulsory OCB based on stress is significantly affected by contextual factors.

Through inducing and analyzing the above four categories of OCBs, we know that OCB might not be completely voluntary behaviors. Under certain circumstances, employees would choose to perform instrumental OCB to benefit 
themselves. The degree of voluntariness of OCB varies, depending on different contextual factors. Thus, we put forward the $5^{\text {th }}$ proposition as follow:

Proposition 5 OCB is not necessarily a voluntary behavior. The degree of voluntariness of $\mathrm{OCB}$ varies, ranging from completely voluntary $\mathrm{OCB}$ to completely compulsory OCB.

\section{Organizational Citizenship Behavior Continuum}

As there are always motives behind people's actions, people will act enthusiastically or reluctantly, depending on whether or not the action can fulfill their purpose (see Ajzen, 1991). OCB is also affected by the performer's subjective intention, and the higher of intention, the more initiative and voluntary of individuals. Through the above analysis, we know that the four categories of OCBs have different characters, and so does the degree of intention when individuals perform OCB. More specifically, determined by personality and performance for intrinsic motivation and altruism, the degree of voluntariness of altruistic OCB based on personality shall be the highest. Affected by social exchange theory and the norm of reciprocity, meanwhile it is duty to pay back other benefaction, the degree of voluntariness of responsible OCB based on reciprocity should come the second highest. Affected by an individual's utilitarianism, people just chose to perform OCB that benefit for themselves, so the degree of voluntariness of instrumental OCB based on self-interest should be third highest. Compelled by outside contextual variables, the degree of voluntariness of compulsory OCB based on stress is the least high.

As alluded to above, people vary in degrees of voluntariness when performing OCB. To reflect these differences visually, we arrange the four subtypes of OCB in the order of voluntariness from the lowest to highest, and construct a sequence. Accordingly, we name this sequence as organizational citizenship behavior continuum (Fig. 1). As shown in the figure, the degree of voluntariness increases gradually from left to right.

\begin{tabular}{|c|c|c|c|}
\hline $\begin{array}{c}\text { Compulsory OCB } \\
\text { based on stress }\end{array}$ & $\begin{array}{c}\text { Instrumental OCB } \\
\text { based on self-interest }\end{array}$ & $\begin{array}{l}\text { Responsible OCB } \\
\text { based on reciprocity }\end{array}$ & $\begin{array}{c}\text { Altruistic OCB } \\
\text { baesd on personality }\end{array}$ \\
\hline
\end{tabular}

Fig .1 Organizational Citizenship Behavior Continuum

Proposition 6 Based on the degree of voluntariness, the four subtypes of $\mathrm{OCB}$ can construct an $\mathrm{OCB}$ continuum. From left to right, this continuum consists of compulsory OCB based on stress, instrumental OCB based on self-interest, responsible OCB based on reciprocity and altruistic OCB based on personality. 


\section{The Potential Consequences of the Organizational Citizenship Behavior Continuum}

Through literature review, we have found that the previous OCB researches mostly focused on the positive effect of OCB from the perspective of organizational performance, neglecting the negative side of these OCBs. Meanwhile, although Bolino et al. (2004) pointed out that OCB might lead to some negative consequences. However, they did not to analyze these consequences from both organizational and individual perspective respectively. In this paper, we propose that different types of OCBs have different impacts on organization and individuals and shall be treated differently (Podsakoff et al., 2009). In next section, we will analyze these positive and negative consequences, respectively.

\subsection{The Potential Consequence of Altruistic OCB Based on Personality}

As discussed earlier, altruistic OCB based on personality is determined by individual's intrinsic motivation. Employees perform this type of OCB just for intrinsic satisfaction and do not care about any returns. Therefore, altruistic OCB absolutely belongs to voluntary behavior. For organization, this type of OCB brings a series positive effects, including uniting coworkers, enhancing productivity and better utilizing scarce resources, etc. Therefore, altruistic OCB can be used for more productive purposes, reducing the need to devote scarce resources to purely maintenance functions, helping to coordinate activities both within and across work groups, strengthening the organization's abilities to attract and retain the best employees, increasing the stability of organization's performance, and enabling an organization to adapt effectively to environmental changes (Podsakoff et al., 2000). In addition, as a voluntary behavior, altruistic OCB does not increase managerial cost. As for the individual level, performing altruistic OCB can not only satisfy employees' intrinsic satisfaction and improve self-efficiency, but also can express their values, gain other's respects. Therefore, its impact on individuals is as positive as it is on organizations.

Proposition 7 The potential impacts of altruistic personality-based OCB on organization and individuals are positive.

\subsection{The Potential Consequence of Responsible OCB Based on Reciprocity}

It has been found that responsible OCB based on reciprocity actually can support the broader organizational, social, and psychological environment in which an organization functions (Organ, 1997). However, responsible OCB based on reciprocity also gives rise to some negative organizational consequences. For 
example, employees have to strictly abide by all organizational rules and regulations to be a "good soldier," but such a blind obedience to authority might sometimes make it difficult for managers find hidden problems, or build up bureaucratic climate in organization, or lead to organizational rigidity (Zhang and Liao, 2009). Similarly, employees performing responsible OCB are less likely to stop coworkers' behaviors which can potentially harm organizational well-being for the sake of harmonious relationship among workers.

The consequences of responsible OCB based on reciprocity for individuals are also double-edged. The positive influences are as follows: responsible OCB based on reciprocity can improve trust, reciprocal relationship between employees and managers, therefore employees can gain more support from managers. Reciprocity is useful for building an individual's social network and increasing individual's social capital. It can also make role responsibility specific, reduce role ambiguity and improve employees' self-efficiency concerning their role-related functions (Becton et al., 2008). The negative influences lie in that the moral bondage of the responsibility to reciprocity will increase individual's psychological burden, because exhibiting the OCB which benefit for organizations and groups is at the cost of individual's long term career development (Bergeron, 2007). Joireman et al. (2006) also pointed out that OCB can be seen as a dilemma which sacrifices employees' long term benefits for achieving organizational long-termed interests. Bolino and Turnley (2005) asserted that performing OCB can result in "escalating citizenship": employees felt obliged to continually perform OCB to maintain their image of good organizational citizen. Consequently, they might feel stressed, overloaded, suffer from role conflict, job stress, work-family conflict, or little time to devote to their personal lives. Under such circumstances, the so-called "good soldier syndrome" happens. Finally, OCB may influence negatively task performance, which in turn leads to a lower performance appraisal and less reward for responsible and reciprocity-based OCB performers. The discussion above is summarized in terms of the following propositions:

Proposition 8 The positive consequences of responsible OCB based on reciprocity for organization and individuals are greater than its negative consequences.

\subsection{The Potential Consequence of Instrumental OCB Based on Self-Interest}

IM is a typical tactic for instrumental OCB based on self-interest. It has been found that employees often take advantage of IM to obtain individual goals, improve self-benefit, implement social control, and change other's behaviors. Therefore, instrumental OCB brings negative impact on organization in the long run. As aforementioned, when evaluating OCBs, some employees might abandon 
altruistic OCB which arises from intrinsic motivation, and turn to IM tactic to perform instrumental OCB (Becton et al., 2008; Zhang and Liao, 2009): "good soldier" becomes "good actor," "genuine OCB" becomes "pseudo OCB" or "superficial OCB" (Leung et al., 2002). Then, it will increase an organization's managerial cost, hinder leaders from finding potential problems, result in lack of organizational fairness, decrease employees' trust to leaders, intensify human conflict and even give rise to some counterproductive work behaviors (Fox et al., 2001). In sum, although instrumental OCB based on self-interest is useful for improving organizational performance, it brings more negative than positive impact on organizations in the long run.

As for the individual level, the potential consequences of instrumental OCB based on self-interest are also double-edged. The positive influences are as follows: In the presence of leaders and coworkers, performing OCB can change other's perception, leave positive impression (Organ, 1988), improve leader-member exchange relationship, get higher performance appraisal (Bolino, 1999), obtain more organizational rewards, position promotion and other benefits. The negative influences lie in that IM may give people an impression of saponaceousness, manipulativeness and unethicalness. In addition, working hard might imply a lack of competence.

Proposition 9 At the organizational level, OCB based on self-interest brings more negative impacts on organization than positive impacts; whereas at the individual level, its positive impact on individuals is greater than its negative impact.

\subsection{The Potential Consequence of Compulsory OCB Based on Stress}

In view of the positive impact of OCB on organizations, managers always adopt some means to encourage or even request employees to perform OCBs. In the practice of management, despite forcing employees to assume extra-role behavior is useful for achieving organizational goal and increasing management efficiency, it also brings negative impact on organizational performance in the long run. Vigoda-Gadot (2007) found that CCB has negative influence on innovation, job satisfaction and performance. Exhibit CCB which is forced by work stress can result in emotion disorder, rage, suspicion and other negative affections, and finally induce emotional exhaustion, which can induce lower job involvement, higher turnover intention and other negative organizational results (Chiu and Tsai, 2006). Fox et al. (2001) asserted that rage, suspicion and other negative emotions can result in absenteeism, pilferage, high turnover rate and other counterproductive work behaviors.

Individually, although compulsory OCB based on stress is useful for establishing an image of "good soldier," employees are unwilling to perform 
these "OCBs." As aforementioned, compulsory OCB is positively related to work stress, and work stress is the most important factor affecting physical and mental health. Shi et al. (2009) held that work stress makes people more vulnerable to diseases like heart attack and high blood pressure, hypertension, insomnia, cardiovascular disease, psychological illnesses and so on. Besides, if employees have to spend much time to deal with work, it also may cause work-family conflict or conflict between work and one's personal life.

Proposition 10 The negative impact of compulsory OCB based on stress on organization and employees are greater than its positive impact.

To summarize, the potential impact of altruistic OCB based on personality on organization and employees are almost positive; the potential positive impact of responsible OCB based on reciprocity on organization and employees are higher than its negative impacts; the potential negative impact of instrumental OCB based on self-interest on organization are higher than that of its positive impact, but the exact opposite is true for individuals; the potential negative impact of compulsory OCB based on stress on organization and employees are both higher than its positive impact. By comparison, we assume that the potential positive impact of altruistic OCB based on personality are highest, responsible OCB based on reciprocity and instrumental OCB based on self-interest follows next, and compulsory OCB based on stress is the lowest. The assumed positive and negative impact of organizational citizenship behavior continuum is shown as follows (Fig. 2).

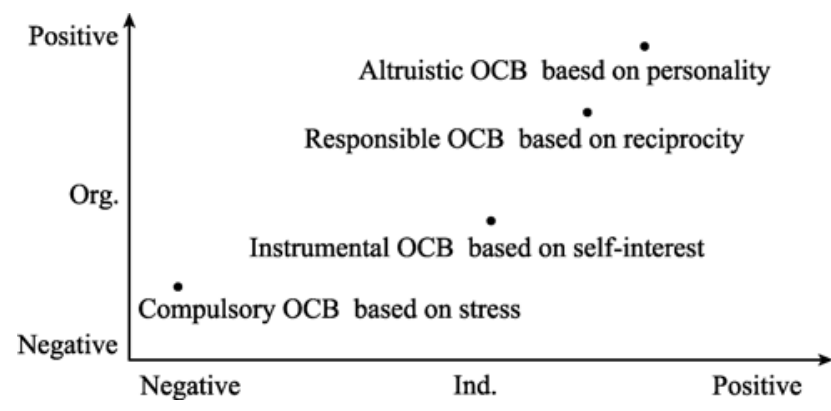

Fig. 2 The Consequence of OCB Continuum for Organization and Employees Note: Above analysis takes long term impacts into account.

In conclusion, the impact of $\mathrm{OCB}$ on organization is not necessarily positive, and under certain circumstances, it may induce certain negative impact on both organizations and individual employees.

Proposition 11 The impact of OCB on organization and employees is not necessarily positive. 


\section{Conclusion and Discussion}

OCB has long been regarded as employees' voluntary and positive behavior, the degree of voluntariness of $\mathrm{OCB}$ and its negative consequences have long been neglected. This paper, for the first time, identifies four subtypes of OCB after a careful review of OCB literature and summarization of managerial practice. Then this paper constructs an OCB continuum based on the degree of voluntariness. Finally, this paper analyzes and compares the potential positive and negative impact of OCB on organization and employees.

This paper proposes several research propositions for future research on OCB subtypes, OCB continuum and the respective impact of these subtypes on organization and individual. From these propositions, we can obtain two important implications: Firstly, there are different types of OCB in organization. Except for altruistic OCB and responsible OCB, instrumental OCB and compulsory $\mathrm{OCB}$ also widely exist in organization. When the environment changes, the last two types of OCB become norms in organizations. This idea is opposite to the traditional idea that OCB is employees' voluntary behaviors. Secondly, OCB might exert double-edged effect on organization and individual: the impact of OCBs on organization and individuals varies with OCB types, challenging the traditional assumption that $\mathrm{OCB}$ only exerts a positive impact on organization performance.

There are several limitations in this paper. Firstly, we just identified four subtypes of OCBs, which might lead to a neglect of other possible OCB subtypes. Secondly, we assumed that the four subtypes of OCBs are independent with each other, neglecting the possibility that these OCBs might overlap with or even convert into each other under certain circumstances. Thirdly, the impact of OCB on organization and employees are very likely to be complicated and long-termed, the propositions concerning OCB continuum in the current paper still lack of empirical validation. Thus, there are two important issues to be solved in the future research. Firstly, to further summarize and abstract the respective characteristics of the above four OCB subtypes. Secondly, a suitable scale to measure the OCB continuum is still needed. Hopefully, we can use the future research results to check the rationality of the above propositions.

Acknowledgements We are thankful to the two anonymous reviewers for their valuable suggestions. This paper is supported by the National Natural Science Foundation of China (No. 70972016).

\section{References}

Ajzen, I. 1991. The theory of planned behavior. Organizational Behavior and Human Decision 
Processes, 50(2): 179-211.

Baker, T. L., Hunt, T. G., \& Andrews, M. C. 2006. Promoting ethical behavior and organizational citizenship behaviors: The influence of corporate ethical values. Journal of Business Research, 59(7): 849-857.

Becton, J. B., Giles, W. F., \& Schraeder M. 2008. Evaluating and rewarding OCBs: Potential consequences of formally incorporating organizational citizenship behavior in performance appraisal and reward systems. Employee Relations, 30(5): 494-514.

Bergeron, D. M. 2007. The potential paradox of organizational citizenship behavior: Good citizens at what cost? Academy of Management Review, 32(4): 1078-1095.

Bolino, M. C. 1999. Citizenship and impression management: Good soldiers or good actors? Academy of Management Review, 24(1): 82-98.

Bolino, M. C., \& Turnley, W. H. 2005. The personal costs of citizenship behavior: The relationship between individual initiative and role overload, job stress, and work-family conflict. Journal of Applied Psychology, 90(4): 740-748.

Bolino, M. C., Turnley, W. H., \& Niehoff, B. P. 2004. The other side of the story: Reexamining prevailing assumptions about organizational citizenship behavior. Human Resource Management Review, 14(2): 229-246.

Borman, W. C., \& Motowidlo, S. J. 1993. Expanding the criterion domain to include elements of contextual performance. San Francisco: Jossey-Bass.

Bozeman, D. P., \& Kacmar, K. M. 1997. A cybernetic model of impression management processes in organizations. Organizational Behavior and Human Decision Processes, 69(1): 9-30.

Brockner, J. 1988. The effects of work layoffs on survivors: Research, theory and practice. Research in Organizational Behavior, 10: 213-255.

Chiu, S. F., \& Tsai, M. C. 2006. Relationships among burnout, job involvement, and organizational citizenship behavior. The Journal of Psychology, 140(6): 517-530.

Finkelstein, M. A. 2006. Dispositional predictors of organizational citizenship behavior: Motives, motive fulfillment, and role identity. Social Behavior and Personality, 34(6): 603-616.

Fox, S., Spector, P. E., \& Miles, D. 2001. Counterproductive work behavior (CWB) in response to job stressors and organizational justice: Some mediator and moderator tests for autonomy and emotions. Journal of Vocational Behavior, 59(3): 291-309.

George, J. M., \& Jones, G. R. 1997. Organizational spontaneity in context. Human Performance, 10: 153-170.

Grant, A., \& Mayer, D. M. 2009. Good soldiers and good actors: Prosocial and impression management motives as interactive predictors of affinitive citizenship behavior. Journal of Applied Psychology, 94(4): 900-912.

Hui, C., Lam, S. K., \& Law, K. S. 2000. Instrumental values of organizational citizenship behavior for promotion: A field quasi-experiment. Journal of Applied Psychology, 85(5): 822-828.

Joireman, J., Kamdar, D., Daniels, D., \& Duell, B. 2006. Good citizens to the end? It depends: empathy and concern with future consequences moderate the impact of a short-term time horizon on organizational citizenship behaviors. Journal of Applied Psychology, 91(6): 1307-1320.

Korsgaard, M. A., Meglino, B. M., Lester, S. W., \& Jeong, S. S. 2010. Paying you back or paying me forward: Understanding rewarded and unrewarded organizational citizenship 
behavior. Journal of Applied Psychology, 95(2): 277-290.

Lavelle, J. J., Rupp, D. E., \& Brockner, J. 2007. Taking a multifoci approach to the study of justice, social exchange, and citizenship behavior: The target similarity model. Journal of Management, 33(6): 841-866.

Leung, K., Koch, P. T., \& Lu, L. 2002. A dualistic model of harmony and its implications for conflict management in Asia. Asia Pacific Journal of Management, 19(2): 201-202.

Moorman, R. H., \& Blakely, G. L. 1995. Individualism-collectivism as individual difference predictor of organizational citizenship behavior. Journal of Organizational Behavior, 16(2): $127-142$.

Organ, D. W. 1998. Organizational citizenship behavior: The good soldier syndrome. Lexington, MA: Lexington Books.

Organ, D. W., \& Ryan, K. 1995. A meta-analytic review of attitudinal and dispositional predictors of organizational citizenship behavior. Personnel Psychology, 48(4): 775-802.

Organ, D. W. 1997. Organizational citizenship behavior: It's construct clean-up time. Human Performance, 10(2): 85-97.

Penner, L. A., Midili, A. R., \& Kegelmeyer, J. 1997. Beyond job attitudes: A personality and social psychology perspective on the causes of organizational citizenship behavior. Human Performance, 10(2): 111-132.

Podsakoff, P. M., MacKenzie, S. B., Paine, J. B., \& Bachrach, D. G. 2000. Organizational citizenship behaviors: A critical review of the theoretical and empirical literature and suggestions for future research. Journal of Management, 26(3): 513-563.

Podsakoff, N. P., Whiting, S. W., Podsakoff, P. M., \& Blume, B. D. 2009. Individual- and organizational-level consequences of organizational citizenship behaviors: A meta-analysis. Journal of Applied Psychology, 94(1): 122-141.

Shi, Y. 时雨, Liu, C. 刘聪, Liu, X. 刘晓倩, \& Shi, K. 时勘. 2009. 工作压力的研究概况 (A review on work stress). 经济与管理研究 (Economy and Management Research), (4): 101-107.

Simona, G., Shirom, A., Fried, Y., \& Cooper, C. 2008. A meta-analysis of work demand stressors and job performance: Examining main and moderating effects. Personnel Psychology, 61(2): 227-271.

Smith, C. A., Organ, D. W., \& Near, J. P. 1983. Organizational citizenship behavior: Its nature and antecedents. Journal of Applied Psychology, 68(4): 653-663.

Snell, R. S., \& Wong, Y. L. 2007. Differentiating good soldiers from good actors. Journal of Management Studies, 44(6): 883-909.

Spector, P. E., \& Fox, S. 2010. Theorizing about the deviant citizen: An attributional explanation of the interplay of organizational citizenship and counterproductive work behavior. Human Resource Management Review, 10(2): 132-143.

Tang, T. L. P., Davis, G. M. T. W., \& Ibrahim, A. H. S. 2008. To help or not to help? The good Samaritan effect and the love of money on helping behavior. Journal of Business Ethics, 82(4): 865-887.

Tumipseed, D. L., \& Wilson, G. L. 2009. From discretionary to required: The migration of organizational citizenship behavior. Journal of Leadership \& Organizational Studies, 15(3): 201-216.

VanDyne, L., Cummings, L. L., \& McLean Parks, J. 1995. Extra-role behavior: In pursuit of construct and definitional clarity. In L. L. Cummings \& B. M. Staw (Eds.), Research in organizational behavior, Vol. 17: 215-285. Greenwich, CT: JAI Press. 
Vigoda-Gadot. 2007. Redrawing the boundaries of OCB? An empirical examination of compulsory extra-role behavior in the workplace. Journal of Business and Psychology, 21(3): 377-405.

Wei, J. 魏江茹. 2006. 好战士还是好演员: 基于印象管理的组织公民行为 (Good soldier or good performer: Organizational citizenship behavior based on impression management). 经 济管理 (Economy Management), (15): 51-53.

Yun, S., Takeuchi, R., \& Liu, W. 2007. Employee self-enhancement motives and job performance behaviors: Investigating the moderating effects of employee role ambiguity and management perceptions of employee commitment. Journal of Applied Psychology, 92(3): 745-756.

Zhang, Y. 张永军, \& Liao, J. 廖建桥. 2009. 组织公民行为考核及影响研究 (Study on organizational citizenship behavior examination and influences). 中国人力资源开发 (Human Resource Development of China), (7): 6-9. 